underweight, and it is particularly undesirable to be overweight. The amount of fat in the body, though no doubt to some extent under endocrine influence, must in practice reflect habits of eating and of activity. Adiposity can be altered in the adult by a suitable regimen, probably with benefit to health. Adult stature, on the other hand, cannot be so altered. If we want to increase the proportion of well-grown and healthy adults in the population, we must improve living conditions and nutrition during growth.

The most important implication of these findings is that it is not sufficient to take care of the diet of women after pregnancy has begun. Nutritional preparation for pregnancy begins in infancy, perhaps even during foetal life.

We thank Professor Daphne Chun, University of Hong Kong, for making available the records from which some of the values in Table 4 were calculated.

\title{
REFERENCES
}

Bernard, R. M. (1952). Edinb. med. F. 59, Proc. Edinb. obstet. Soc. p. I.

Boyne, A. W. \& Leitch, I. (I954). Nutr. Abstr. Rev. 24, 255.

Thomson, A. M. (1959). Eugen. Rev. 5I, 3.

Thomson, A. M. \& Billewicz, W. Z. (196r). Brit. F. Nutr. 15, 24 I.

Thomson, A. M., Billewicz, W. Z. \& Passmore, R. (I961). Lancet, i, 1027.

Thomson, A. M. \& Duncan, D. L. (1954). Nutr. Abstr. Rev. 24, I.

Thomson, A. M. \& Hytten, F. E. (1961). Proc. Nutr. Soc. 2o, 76.

\section{Some considerations of changes in total body composition in relation to nutritional status}

\section{By H. B. Anstall, Postgraduate Medical School of London, Hammersmith Hospital, London, W.12}

The science of physiology is concerned with the elucidation of the various problems of body function. It comprises many facets, each of them in its own way a speciality, but collectively making up a singularly complex whole. Each of these facets has its own associated techniques, making use of the principles of physics, chemistry, and other sciences. If physiology is to be truly quantitative, means must be devised for the analysis of the body as a whole, i.e. as a living functional unit. Thus there devolves upon us the problem of establishing methods for measuring the magnitude of its various components. For the true understanding of such variations in body composition as occur in nutritional aberrations, it is necessary first to define the normal situation regarding the chemical composition of the body and then to try to find ways of assessing the nature of departures from this state.

Much has been done in the various aspects of this problem. A detailed discussion of the techniques used and the calculation of individual values is beyond the scope of this short communication. What is proposed is to present a short review of the principal methods used for measuring major body components.

The living body is made up of various functional compartments. It is necessary to distinguish between the mainly active components and the mainly inert. Briefly 
the body may be said to comprise a dynamic (cellular) mass, including the intracellular fluid, and a mass of relatively inert components such as the depot fat, bone mineral, skin, nails, teeth, hair, and the extracellular fluid.

The dynamic mass is of relatively constant composition, comprising essentially a system of protein dispersed in water. The extracellular fluid and fat are highly variable, unlike the other body components. Direct methods of analysis have been carried out extensively on animals but only rarely on human cadavers. Some results, averages from the best-known studies, are shown with some reservations in Table I. These may serve as a point of reference for comparison with results of indirect studies on the living body.

Table I. Values obtained from the direct analysis of human cadavers

\begin{tabular}{lcc}
\multicolumn{1}{c}{ Component } & $\begin{array}{c}\text { Percentage } \\
\text { of total } \\
\text { body-weight }\end{array}$ & $\begin{array}{c}\text { Percentage } \\
\text { of fat-free } \\
\text { body-weight }\end{array}$ \\
Water & 57.6 & $71 \cdot 4$ \\
Fat (ether-extractable fraction) & 19.3 & - \\
Protein (nitrogen $\times 6.25)$ & 16.5 & 19.8 \\
Ash & 7.0 & $8 \cdot 5$
\end{tabular}

\section{Measurement of body fluids}

Indirect techniques are necessarily employed with the living subject. Straightforward methods employing the principle of dilution are available for body fluid determination. In these methods, a test substance, physiologically inert and distributed throughout either the total body water or some defined fraction of it, is administered, and after an interval for equilibration the amount of the material in the plasma is measured. A simple calculation will then give the total volume in which the dose has been diluted. Table 2 shows a selection of test substances used for measuring the compartments of the body water. A brief comment on the use of some of them is called for here.

An ideal test solute should have the following attributes: (I) it must be freely soluble in, or uniformly distributed throughout, those fluid compartments that are being measured; (2) it must not combine with other body components; (3) it must be excreted at an easily measurable rate; (4) it must not be toxic; (5) it must be easily estimated in the plasma.

For measuring total body fluid, of the solutes listed alcohol is discounted because it is metabolized at too high a rate and because it is very difficult to estimate it reliably in plasma (Keys \& Brožek, r953). Urea has been critized on the basis that the ratio of distribution between red cells and plasma is not unity in the postabsorptive state (Ralls, 1943). In any event, it has been superseded by better solutes. Sulphanilamide (Painter, 1940) gives results in fair agreement with desiccation studies in animals but is not really satisfactory as it disappears progressively in the body. Antipyrine (Brodie, Axelrod, Soberman \& Levy, 1949) has long been used for estimation of total body fluid. Uniformly and rapidly distributed throughout the fluid compartments, of low toxicity and easily measured in the plasma, it fulfils well the 
criteria of a good test solute. Experiments on ascitic patients before and after paracentesis show it to be reliable in measuring large and rapid changes in body water (Steele, Berger, Dunning \& Brodie, 1950). Again, in comparison with deuterium oxide, the risk of overestimating fluid volume due to the small protein-binding activity of antipyrine seems to be less than that due to hydrogen-deuterium exchange in the body (Soberman, Brodie, Levy, Axelrod, Hollander \& Steele, 1949). On the other hand, antipyrine has the disadvantage of being slightly soluble in fat.

Table 2. Solutes used for measurement of fiud compartments in man, with mean values found

Test substance
or label
${ }^{2} \mathrm{H}_{2} \mathrm{O}$
${ }^{3} \mathrm{H}_{2} \mathrm{O}$
Antipyrine
Thiocyanate
${ }^{24} \mathrm{Na}$
${ }^{\text {Inulin }}$
${ }^{82} \mathrm{Br}$
Evan's blue
${ }^{131} \mathrm{I}$

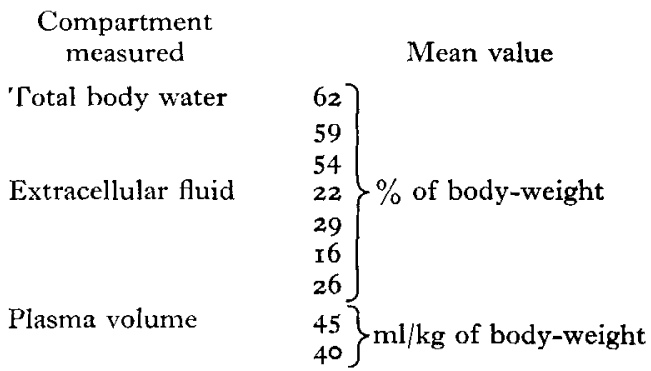

Deuterium oxide (heavy water, ${ }^{2} \mathrm{H}_{2} \mathrm{O}$ ) (Hevesy \& Hofer, 1934) has the disadvantage that deuterium may exchange with labile hydrogen atoms in the body. This exchange can lead to errors as great as $2 \%$ of the total body-weight (Prentice, Siri, Berlin, Hyde, Parsons, Joiner \& Lawrence, 1952). Again, the techniques used for its measurement, by mass spectrometer (Solomon, Edelman \& Soloway, 1950) or the falling-drop method (Schloerb, Friis-Hansen, Edelman, Solomon \& Moore 1950) require much expensive equipment and considerable expertise. Tritiumlabelled water $\left({ }^{3} \mathrm{H}_{2} \mathrm{O}\right)$ is used extensively and, since the radioactivity of tritium is easily measured, this substance is a valuable solute, though there is still some exchange of tritium for hydrogen.

For extracellular fluid, the lowest values are obtained with inulin as solute, thiocyanate giving values about $30 \%$ higher, and other solutes giving values which are somewhat higher still (Table 2). ${ }^{82} \mathrm{Br}$ is used extensively for this determination (McMurrey, Boling, Davis, Parker, Magnus, Ball \& Moore, 1958). Bromide, like chloride, is able to enter the red cells to a significant extent (McMurrey et al. I958) and a correction involving measurement of plasma and red-cell volume is desirable for greatest accuracy. A correction factor for effects due to the Donnan equilibrium must also be used.

Plasma volume is measured either by the use of the dye, Evan's blue, or more reliably with ${ }^{131}$ I-labelled albumin.

By a suitable combination of tests of this kind, it is possible to obtain over a short period a number of quantitative values. Thus by using ${ }^{51} \mathrm{Cr},{ }^{2} \mathrm{H}_{2} \mathrm{O}$ or ${ }^{3} \mathrm{H}_{2} \mathrm{O},{ }^{82} \mathrm{Br}$, ${ }^{131}$ I-labelled albumin, ${ }^{24} \mathrm{Na}$, and ${ }^{42} \mathrm{~K}$ it is possible to determine successively total body water, blood and plasma volume, red-cell volume, and total exchangeable 
$\mathrm{Na}$ and $\mathrm{K}$, and from these values the total body fat and the fat-free solids can be derived.

\section{The measurement of body fat}

The problem of body fat measurement is more complex. Ideally, if a fat-soluble substance could be found that was concentrated exclusively in fat, then its concentration in subcutaneous fat at equilibrium would be a good measure of total body fat. No such indicator has yet been found, though fairly good results have been obtained in animals with cyclopropane, and in man with ${ }^{85} \mathrm{Kr}$ (radioactive krypton) (Lesser, Blumberg \& Steele, I952; Bradley, Davidsson, MacIntyre \& Rapoport, I 956).

In general it may be said that gas methods for the measurement of total body fat are promising but they are not yet satisfactorily developed. They are, however, undoubtedly the most promising of the various techniques available.

More indirect methods have given good results for body fat. Two broad principles apply, namely the computation of body fat from body-water measurements and the determination of fat by densitometry.

Computation of body fat from body fluids. The various solutes for total body water and extracellular fluid measurement have been considered already. The method for fat employs the concept that a fat-free body has a relatively fixed composition, an assumption that is supported by experimental data obtained from animals under widely differing nutritional conditions (Murray, I922; Moulton, I923). Thus if the total body fluid is measured it would allow measurement of the fat-free body-weight, the difference between it and the gross weight giving the total body fat. Support for the method comes from the data of Pace \& Rathbun (1945) and it has been confirmed by density measurements. From their results Pace \& Rathbun conclude that about $73 \%$ of the fat-free body mass is water, and that the fat-free body mass has an effective density of $\mathrm{I} \cdot 099$. They derived a formula

$$
\text { Fat }(\%)=100-\frac{\text { total body water }(\%)}{0.73^{2}} \text {, }
$$

from which the value for fat can be calculated. The method becomes invalid when hydration abnormalities such as oedema exist, though some degree of correction is obtained by estimating the extracellular water.

Computation of body fat from body density. Since fat is of lower density than other body components, the greater the amount of fat in the body the lower is the effective density of the body. Now density (D) of a body is mass/unit volume, and the denominator of this expression can be measured accurately by the application of Archimedes's principle, which states that the difference between the weight of a body in air and its weight when immersed in water is equal to the weight of water displaced. The body volume so found should be corrected for the volume of the residual air in the lungs, which is measured separately. From the body volume and the density of water at the temperature obtaining in the immersion tank, and also from the density of human body fat at a mean body temperature of $36^{\circ}$, the total body fat can be calculated. Keys \& Brožek (1953) have found a mean value for the density of human fat at $36^{\circ}$ of $0.9008 \mathrm{~g} / \mathrm{ml}$. The value for the density of the fat-free portion 
of the body is more difficult to determine. Knowledge of this value is essential for the computation of fat from body density measurements, but it is clear that it cannot be determined with absolute certainty. However, animal data, together with the few figures available from direct chemical analyses of human cadavers, show that it has a relatively constant value. Bone mineral is remarkably constant in several species, and mean figures from direct analyses may be used without too much inaccuracy. The main variable is the water, especially the extracellular fluid. In practice, when densitometry is used and any hydration anomaly exists, the extracellular fluid must be measured, since oedema fluid has a density of the order of 1.002 at $36^{\circ}$, and allowance must be made for it.

Pace \& Rathbun (I945), computing supposedly reasonable values from direct analysis of human cadavers, proposed a formula for the calculation of body fat thus:

$$
\text { Fat }(\%)=100 \times\left(\frac{5.548}{\text { sp.gr. }}-5.044\right) \text { at } 25^{\circ} \text {. }
$$

If this formula is adapted to take into account the mean density of fat at $36^{\circ}$ it becomes

$$
\text { Fat }=\frac{5^{\circ} \cdot 03^{8}}{D}-4.593 \text { (Keys \& Brožek, 1953). }
$$

This calculation is open to the criticism that when the body gains or loses weight not only the fat content changes, for the density of the tissue gained or lost is quite different from that of the pure fat. This obesity tissue, as it may be called, has a relatively fixed density, and the amount of this tissue could be calculated from the gross density if the density of a body of standard composition could be fixed. This concept would imply a healthy subject, neither fat nor thin, and most suitably corresponding to the mean of healthy young adults conforming most exactly to the mean weight for height for their age group. Brožek (1952) gives a computed value for this density of $\mathrm{I} \cdot 0629 \pm 0.0025^{2} \mathrm{~g} / \mathrm{ml}$. From this value it is possible to obtain a reasonable value for the weight of obesity tissue, which constitutes a real measure of weight gain. The situation can be further improved by measuring the extracellular fluid.

The problem of absolute fat values is still unsolved, nor can it be truly decided until the precise fat content of a standard reference body is known. Yet, despite the limitations imposed by circumstance, these various techniques provide valuable means for assessing quantitatively such changes in gross body composition as occur under varied nutritional conditions.

\section{Practical applications of the techniques}

We have been concerned chiefly with measurement of variable body components by different indirect methods. The main applications of these methods are largely self-evident. Determination of the magnitude of the body fluid compartments is valuable in assessing the state of hydration, and measurements of blood and plasma volume may help to form conclusions regarding the dynamic state of the circulation, 
the degree of haemoconcentration, and so on, in a variety of clinical disorders. Electrolyte studies of the type referred to are extremely valuable as research procedures and may be applied to specific problems of electrolyte balance and exchange.

Of more direct concern with nutritional status are the measurements of total body fat. Important applications of these measurements are the analyses of weight changes and the interpretation and correction of estimations of the metabolic rate. Analysis of body composition enables comparisons to be made between both individuals and groups of individuals, and these comparisons are of far greater quantitative value than mere height-weight comparisons. With the acceptance of the concept of a mean, or standard, reference body, as discussed above, one individual may be compared fairly with another. Thus valuable quantitative data, regarding the nature of the changes in weight which result from alterations in the diet, may be obtained, and in this respect interesting data have come to light.

Keys, Brožek, Henschel, Mickelsen \& Taylor (1950) and Keys \& Brožek (1953) have shown that patterns of weight gain differ according to the initial status of the individual. When the gain results from refeeding after a fairly prolonged period of semi-starvation, as in the Minnesota experiment (Keys et al. 1950), in the first few weeks after resumption of feeding assessment of body composition showed little change in the extracellular fluid volume, despite a substantial weight gain, which was due to the deposition of fat (accounting for roughly half the increase) and to cellular (non-fat) tissue. As time progressed the laying down of fat outstripped the formation of cellular substance, but in the final stage the excess of fat was replaced by cellular material. Gain in weight from overeating, however, shows a different pattern, since assessment has shown that the principle changes are (I) a substantial increase in the extracellular fluid volume, (2) a considerable increase in fat, and (3) a moderate, though less conspicuous gain in cellular substance.

In weight loss, similar conditions apply. When initially the subject is obese, the earliest losses with a restricted intake of calories may be due almost entirely to loss of fat, but if the deficit of calories is increased, the tissue lost contains an increasing proportion of cellular material; this sequence is confirmed by nitrogen balance studies. With non-obese persons this behaviour is more apparent from the first. Moreover, in both obese and non-obese subjects, extracellular fluid fluctuations are wide, and in true starvation they range from reduction to hunger oedema.

Basal metabolism decreases with increasing age. It has been shown that much of this apparent decrease results not so much from a reduced energy output from cellular metabolism, but from an increase with age in the proportion of fat and extracellular fluid. Again, sex differences in basal metabolic rate can be similarly explained, because, if metabolic rate is expressed in units of fat-free body mass instead of surface area, age and sex differences are largely ironed out.

These then are the principal practical applications of the techniques used for quantitative body analysis. With further technical advances it is to be hoped that modifications in some of the methods for measurement of fat will allow a more widespread application of the techniques, and that they may be more readily used in 22 (1) 6 
individual clinical problems. Nonetheless they do form collectively a useful physiological tool for defining more sharply the gross nature of the chemical relationships which occur in the body under different conditions of nutrition.

\section{REFERENCES}

Bradley, J. E. S., Davidsson, D., MacIntyre, I. \& Rapoport, A. (1956). Biochem. F. 62, 33 P.

Brodie, B. B., Axelrod, J., Soberman, R. \& Levy, B. B. (1949). F. biol. Chem. 179, 25.

Brožek, J. (1952). Fed. Proc. Ix, 784.

Hevesy, G. \& Hofer, E. (1934). Nature, Lond, r34, 879.

Keys, A. \& Brožek, J. (1953). Physiol. Rev. 33, 245.

Keys, A., Brožek, J., Henschel, A., Mickelsen, O. \& Taylor, H. L. (1950). The Biology of Human Starvation. Minneapolis: University of Minnesota Press.

Lesser, G. T., Blumberg, A. G. \& Steele, J. M. (1952). Amer. F. Physiol. 169, 545.

McMurrey, J. D., Boling, E. A., Davis, J. M., Parker, V. H., Magnus, I. C., Ball, M. R. \& Moore, F. D. (1958). Metabolism, 7, 661.

Moulton, C. R. (1923). F. biol. Chem. 57, 79.

Murray, J. A. (1922). F. agric. Sci. 12, 103.

Pace, N. \& Rathbun, E. N. (1945). F. biol. Chem. 158, 685.

Painter, E. E. (1940). Amer, F. Physiol. 129, 744.

Prentice, T. C., Siri, W., Berlin, N. I., Hyde, G. M., Parsons, R. J., Joiner, E. E. \& I awrence, J. H. (1952). F. clin. Invest. 31, $4 \mathrm{I} 2$.

Ralls, J. O. (1943). F. biol. Chem. r51, 529.

Schloerb, P. R., Friis-Hansen, B. J., Edelman, I. S., Solomon, A. K. \& Moore, F. D. (1950). F. clin. Invest. 29, 1296.

Soberman, R., Brodie, B. B., Levy, B. B., Axelrod, J., Hollander, V. \& Steele, J. M. (1949). F. biol. Chem. I79, $3 \mathrm{I}$.

Solomon, A. K., Edelman, I. S. \& Soloway, S. (1950). F. clin. Invest. 29, I3 II.

Steele, J. M., Berger, E. Y., Dunning, M. F. \& Brodie, B. B. (1950). Amer. F. Physiol. 162, 3 I 3.

\section{The assessment of marginal protein malnutrition}

\section{By J. C. WATERLow, * M.R.C. Tropical Metabolism Research Unit, University of the West Indies, Famaica}

Everyone at this meeting knows the importance of protein-calorie malnutrition as a world problem. In the last few years the focus of interest has been shifting from the severe to the milder cases. In the advanced stages mortality is still high, and there are many aspects of the syndrome that are not understood. Nevertheless, in relation to practical public health the problem of marginal malnutrition is the more urgent. Without some reasonably accurate means of assessing nutritional status with respect to protein it is impossible to plan preventive measures in an accurate or economical way. An enormous effort has been put into supplementary feeding programmes in different parts of the world, but because methods of evaluation are so crude we do not really know how effective these programmes have been.

To assess marginal protein malnutrition we must know what are the characteristics of the protein-depleted body, and for this purpose it is logical to work back from severe to mild changes. It may be useful as a background, therefore, to begin by summarizing some of the relevant findings in advanced cases (see Waterlow, Cravioto \& Stephen, r960).

*Present address: clo Department of Chemical Pathology, St Mary's Hospital, London, W.2. 